A look at the region

\title{
The Tracing the Potter's Wheel Project (TPW): An Integrated Archaeological Investigation of the Potter's Wheel in the Bronze Age Aegean
}

\author{
Jill Hilditch $^{1 *}$, Caroline Jeffra ${ }^{1}$, Loes Opgenhaffen ${ }^{1}$ \\ ${ }^{1}$ ACASA - Archaeology, Faculty of Humanities, University of Amsterdam, PO Box 94203, 1090 GE Amsterdam, The Netherlands
}

\section{A RTICLE INFO}

\section{Article history:}

Received: $13^{\text {th }}$ February 2021

Accepted: $25^{\text {th }}$ March 2021

DOI: http://dx.doi.org/10.24916/iansa.2021.2.17

Key words:

ceramic analysis

digital archaeology

experimental archaeology

open access reference collection

potting technology

$3 \mathrm{D}$ visualisation

\begin{abstract}
$A B S T R A C T$
This backstory article discusses the work of the Tracing the Potter's Wheel Project (TPW), an integrated archaeological research project using the potter's wheel as a prism through which to investigate the transmission of craft knowledge in the Bronze Age Aegean. The TPW methodology integrates theoretical perspectives on social interactions, technological processes and innovation, with experimental, 3D digital and analytical methods for visualising and interpreting ceramics. Two central goals have emerged: to provide high-quality resources and standardised guidelines for researchers to learn how to technologically assess assemblages in their own research, and to broadly define the nature of the uptake and use of the pottery wheel in the Aegean during the Late Bronze Age.
\end{abstract}

\section{Introduction}

The Tracing the Potter's Wheel (TPW) project is designed to identify and assess the appearance of the potter's wheel as a technological innovation within the Bronze Age Aegean (2500-1200 BC). The project is funded in the form of an NWO-Vidi grant (2016-2021: PI, J. Hilditch) and hosted by the University of Amsterdam (UvA) within the Amsterdam Centre for Ancient Studies and Archaeology (ACASA) of the Faculty of Humanities. The project uses the potter's wheel as a prism through which to investigate the transmission of craft knowledge and consider the ways Aegean (potting) communities were configured and connected through time. Through sustained archaeological investigation and the creation of fine-grained chronological sequences, the Bronze Age Aegean offers a valuable arena for assessing the dynamics behind past cultural encounters and interaction networks. A key TPW objective is to better understand the interactions that facilitated the transmission of the potter's wheel in this region.

Identifying the use of the potter's wheel within a ceramic assemblage is only the start of the process for reconstructing

*Corresponding author. E-mail: j.r.hilditch@uva.nl the interactions through which this technology was adopted and adapted. To assess whether the potter's wheel was used by local potters, rather than merely appearing as imported wheel-made pots, all vessels with wheel traces must be situated within the local ceramic production sequence or chaîne opératoire, both compositionally and technologically. The method of wheel use is also important for assessing transmission of technical knowledge, as wheel-coiling (or wheel-finishing) is distinct from the wheel-throwing technique, requiring different physical gestures and technical know-how. Indeed, the transition from wheel-coiling to wheel-throwing remains a poorly understood and rarely explored technological development generally. The scope of these project research questions has driven the development of resources for future work, including an open access archive for compositional and technological features of wheelmade ceramics (both experimental and archaeological). Digital archiving strategies also play a key role, both for visualising project research results and promoting public engagement with technological approaches to material culture. Following this strategy, the TPW archive has been built to serve as a dynamic learning tool for specialists and non-specialists alike. The integration of experimental, 


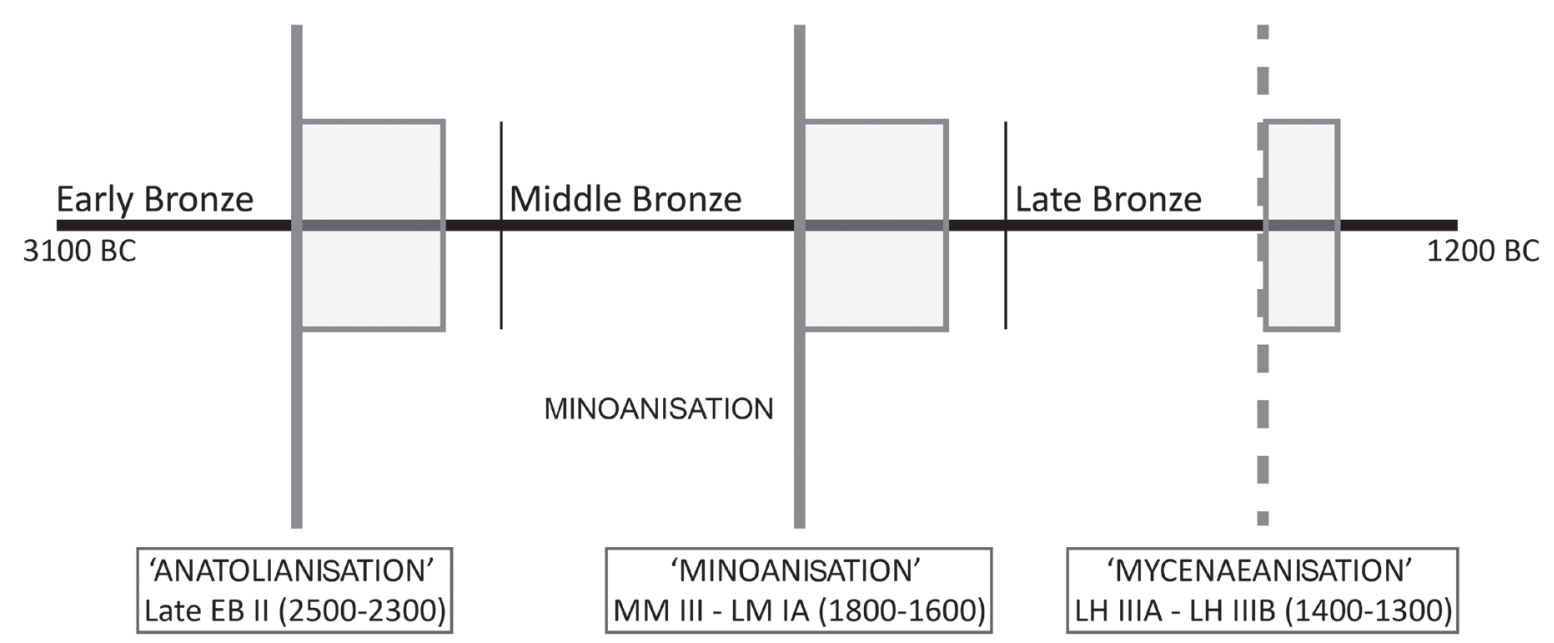

Figure 1. The three chronological transitions in the Bronze Age Aegean in which potting wheel technology has been discussed. Image: J. Hilditch.

technological and digital datasets will ultimately help to refine the identification of wheel-use strategies within the archaeological assemblages under study and subsequently assess the development of these strategies in the Late Bronze Age Aegean.

\section{Regional context for the case study}

The appearance of the potter's wheel in the Bronze Age Aegean has been understood as two potentially independent events, which relate to two different chronological horizons (Knappett, 1999; Choleva, 2012; Rutter, 2013). The first horizon belongs to the Lefkandi I/Kastri phase of the later

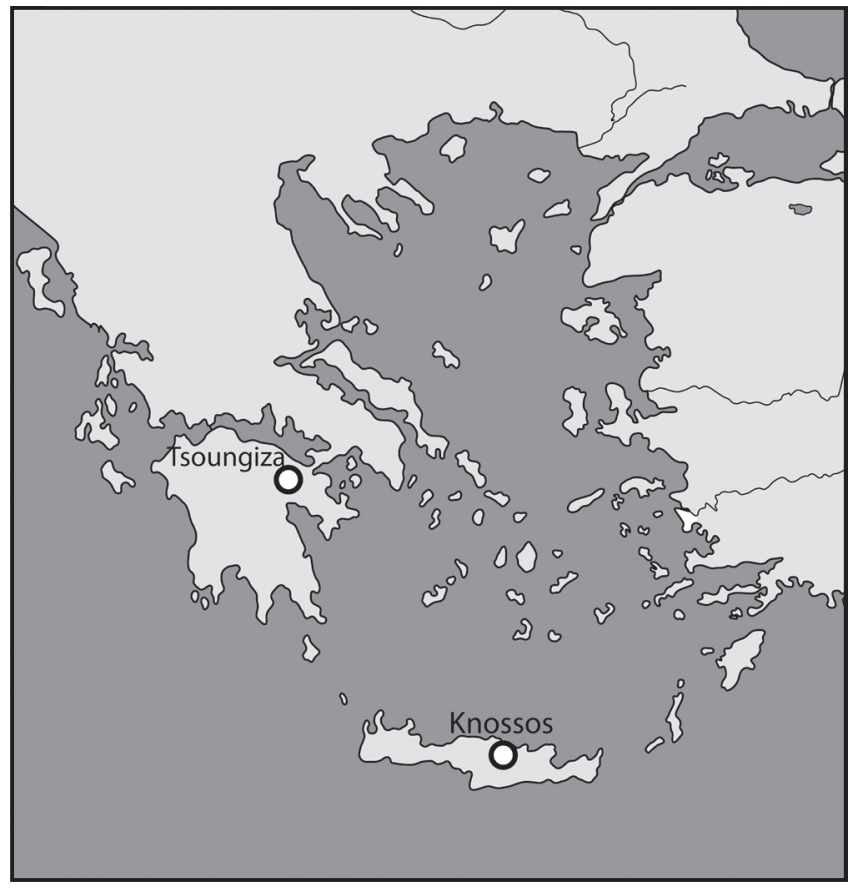

Figure 2. The Aegean and the locations of Tsoungiza and Knossos. Image: L. Opgenhaffen.
Early Bronze (EB) II period, widely interpreted as resulting from increased trade in metals between groups in the Aegean and western Anatolia (Renfrew, 1972; Sotirakopoulou, 1993). The vessels of this phase are known as "Anatolianising" (Şahoğlu, 2007). In the second horizon, the wheel is perceived as a Minoan technology, distributed beyond the borders of Crete as part of a technological package attesting to growing Minoan power and influence within the southern and central Aegean (Minoanisation - Hägg and Marinatos, 1984; Macdonald et al., 2009; Gorogianni et al., 2016) Figure 1.

Recent analysis supports the use of wheel-coiling during the first use of the potter's wheel in the Near East and Aegean regions (Roux, 2003; 2009; Roux and Jeffra, 2015; Jeffra, 2013; 2019; Choleva, 2012). This technique exists alongside other handmade techniques during the later phase of the EB II right up until the end of the Bronze Age (Choleva, 2018; 2020; Choleva, Jung and Kardamaki, 2020; Jeffra, 2013; 2019). Our understanding of the transition from wheel-coiling to wheel-throwing throughout the Aegean, however, is still based upon the traditional narrative of an increasingly broad adoption of the potter's wheel as a manufacturing technology across the region, culminating in mastery of the wheel-throwing technique by Mycenaean communities of the mature Late Bronze (LB) period. Yet the development of this innovation, when and how potters learned to centre a lump of clay on the wheel in order to draw up a pot rather than rotating a preformed (coiled) roughout, remains assumed rather than empirically supported.

Two major Aegean settlements with ideal ceramic datasets were chosen to investigate the development and transmission of the potter's wheel in this region: Knossos on the island of Crete, and Tsoungiza in the Argolid (see Figure 2). Both settlements have yielded rich, diachronic ceramic assemblages spanning (at least) the EB to the latest phases of the LB period, and offer valuable insights on the nature of Minoan and Mycenaean ceramic communities of practice. At each settlement, TPW will focus on the ceramic deposits 
IANSA $2021 \bullet X I L / 2 \cdot 345-355$
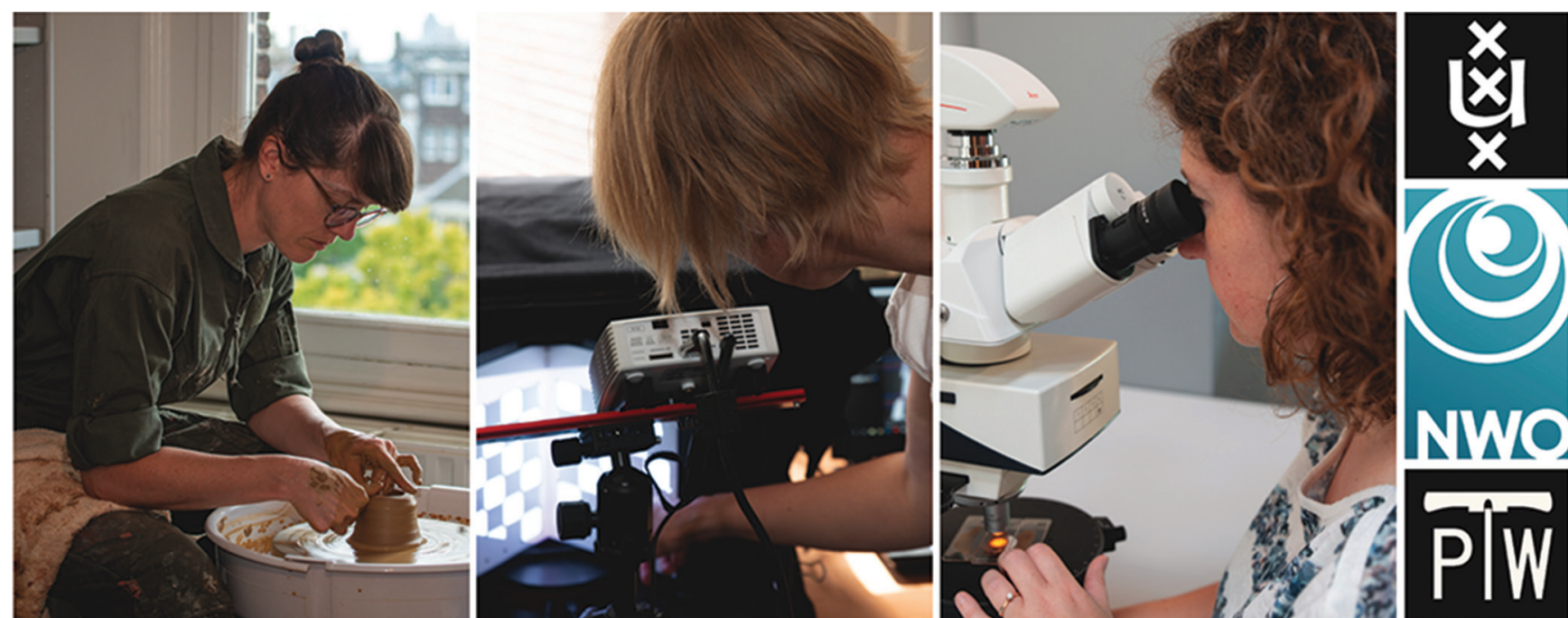

Figure 3. The experiment, 3D visualisation and fabric analysis components of the Tracing the Potter's Wheel Project. Image: J. Hilditch and A. Dekker.
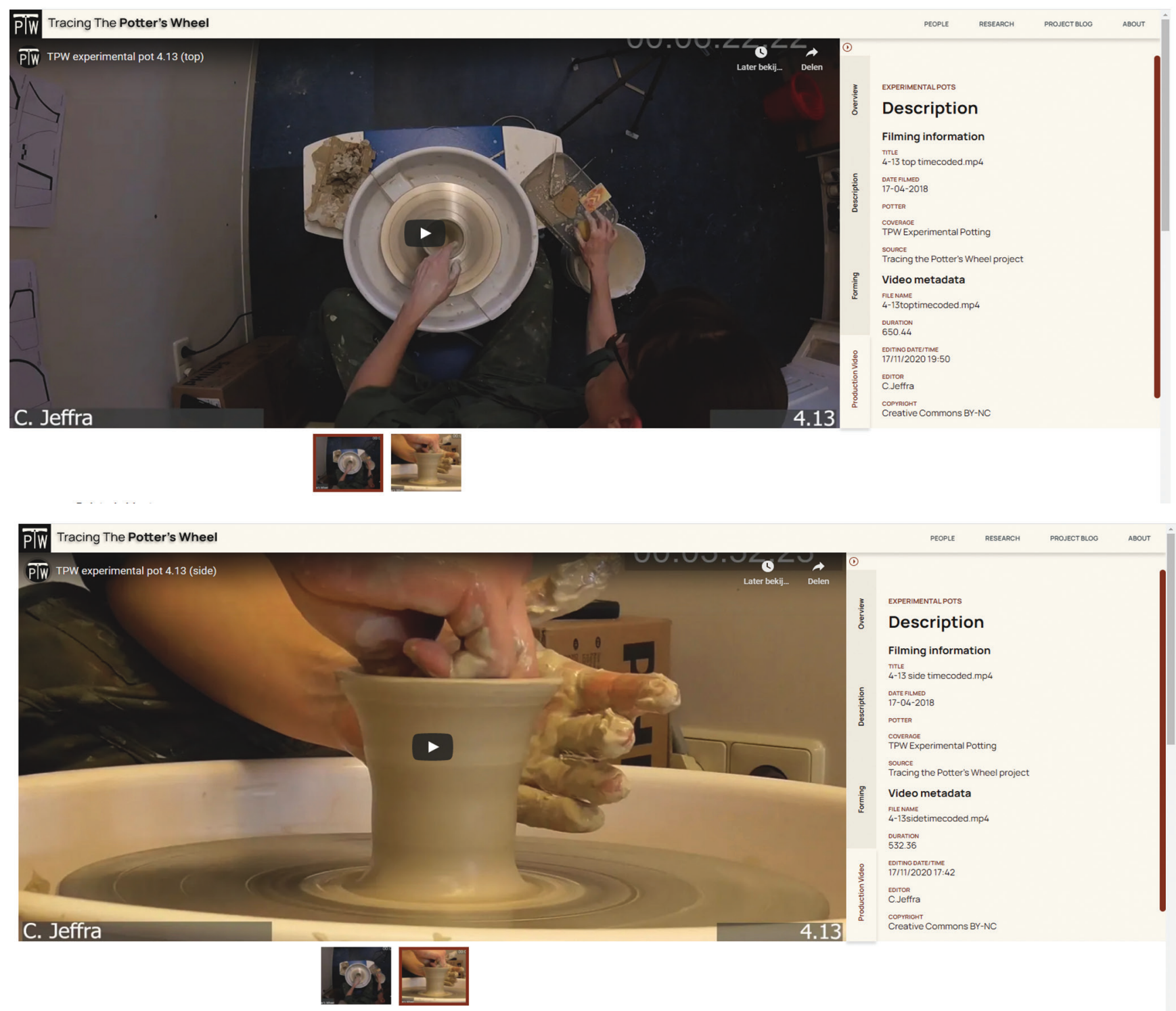

Figure 4. Example of videos of the potting process filmed from two different angles, available via https://tracingthewheel.eu/database/. Image: C. Jeffra. 
from the later Middle Bronze (MB) to the final phases of the $\mathrm{LB}$, to empirically assess the presence and nature of wheel use, as well as identify the potential transition between wheel-coiling and wheel-throwing techniques.

\section{Methodology}

\subsection{Research components}

In order to investigate where, how, and when, specific types of wheel technique appeared within the Bronze Age Aegean, the TPW methodology integrates theoretical perspectives on social interactions, technological processes and innovation, with experimental, 3D digital and analytical methods for visualising and interpreting ceramics. There are three core components within this methodology: experiment, fabric analysis and digital archaeology (see Figure 3). This integrated approach allows the identification (presence, type), characterisation (local/import), and visualisation (knowledge sharing and dissemination) of wheel use within past potting communities.

\subsubsection{Experiment}

The experimental component of the Tracing the Potter's Wheel project involved hypothesis testing using comparative material: it addressed the extent to which it is possible to successfully identify different potting techniques in archaeological material based on experimental material. This required the production of a generalised typeset of vessels, their shapes determined by the presence of specific geometric morphology on specific zones (Jeffra, this volume). By representing the potential range of variation of vessel shapes, this typeset contained suitable analogues for the archaeological material of the Bronze Age Aegean as well as many other contexts. Commercially available clay was used to further support this aim of broad comparability, but two types were selected: fine untempered and tempered with $2.0 \mathrm{~mm}$ grog. Vessels were either wheel coiled or wheel thrown, and each unique combination of vessel shape/forming technique/clay was created several times. The potting process itself was filmed from several angles in order to capture habitual gestures and unconscious practices explicitly (see Figure 4). Experimental vessels were then fired and studied using protocols identical to those applied to archaeological material. This extensive and well-recorded comparative collection was then used to establish details of the chaîne opératoire for archaeological assemblages.

Comparison against archaeological material specifically required the development of a recording protocol. This took the form of standardised photography conditions, applied to experimental and archaeological objects alike. Vessels were photographed in a light-reducing photo box where a flashlight was used to cast controlled shadows across the surface from different angles. These photographs are a durable record of the morphology of surface traces which are often difficult to discern unless material is directly handled. By comparing traces on experimental vessels against those on archaeological vessels, it is possible to gain a stronger understanding of the forming techniques used by ancient potters.

\subsubsection{Fabric analysis}

Once traces of wheel use have been identified on an archaeological vessel, the next step is to ask where this vessel has come from: was it made locally to where it was found, using geologically compatible raw materials, or was it imported? This question is crucial for investigating where the practice of wheel use took place, and whether the technical knowledge of how to use a potter's wheel was present at the find site. A combination of compositional and technological analysis (ceramic fabric analysis: see Whitbread, 2017 for a summary) is used to determine vessel provenance (Figure 5). First, local compatibility, geologically, to the surrounding area of a site is investigated, and then if the clay paste of the wheel-made vessel represents particular processing behaviours of those raw materials. Where geological compatibility cannot be established, the vessel is assumed to be imported and its provenance is then
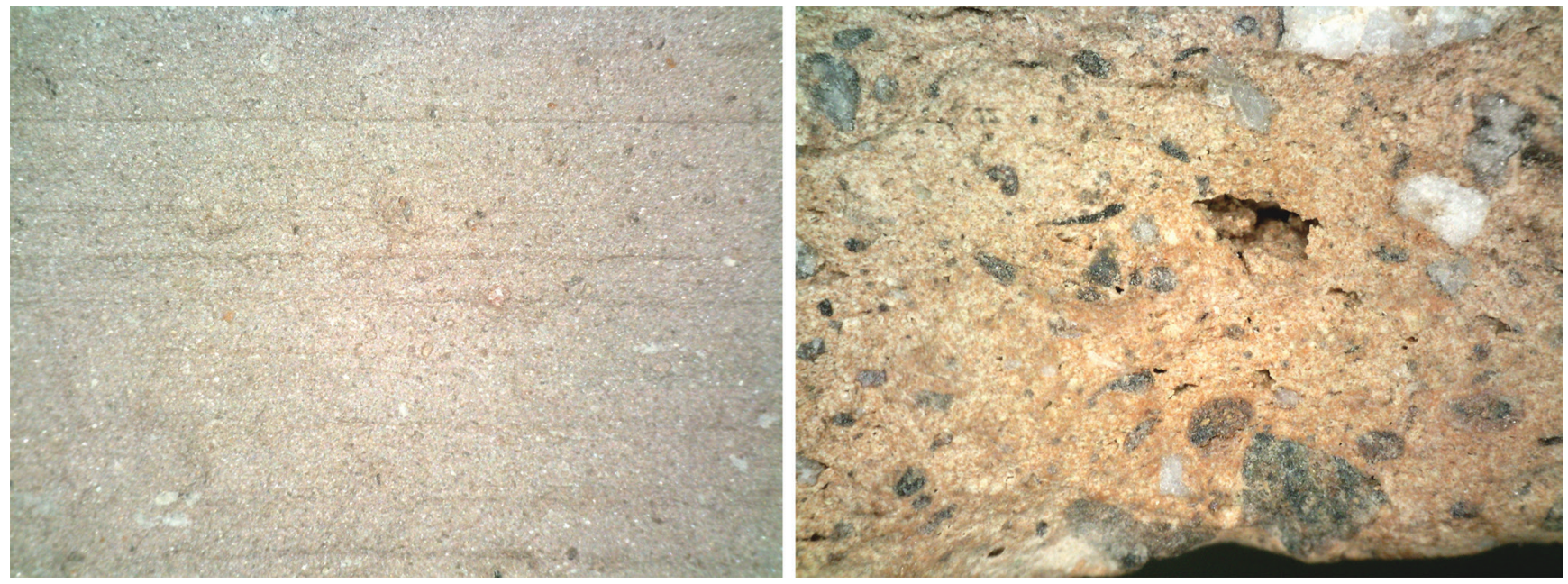

Figure 5. Digital microscope image of a ceramic fabric, showing a surface image (left) and a section break (right) from the same pot. Image: J. Hilditch. 
investigated using comparative fabric analyses from other ceramic assemblages, in combination with typological and stylistic characteristics.

By establishing a local vs. imported provenance for wheel-formed vessels within their find contexts, instances of technological transmission of the potter's wheel can be contrasted against - and interpreted in light of - choices in the distribution and consumption of identified imported wheel-formed vessels (Hilditch, 2019). The trajectories of transmission for the potter's wheel can then be mapped through time. This methodology is rooted in attaining an understanding of local production sequences (chaînes opératoires) for local ceramic products, and their respective communities of practice, as well as distribution networks and consumption choices that were taken in relation to wheel-made vessels. Uncovering the socio-technological choices within communities that used wheel technology, and consumed its products, are crucial for reconstructing the interaction pathways through which the potter's wheel spread.

\subsubsection{D visualisation}

High-resolution 3D scanning can enhance manual, traditional detection methods of macroscopic surface features. Perhaps the greatest advantage of 3D models is that objects can be inspected and analysed outside of their original context, in a virtual environment, using similar tools such as lighting and measuring, reinforced with digital tools such as feature enhancement algorithms (Figure 6). Both archaeological and experimental vessels are well suited for 3D scanning techniques. The TPW experimental ceramic dataset has been scanned in 3D to build an online reference collection of shapes and macrotraces where pottery can be compared with the online examples. Currently TPW uses the commercial platform Sketchfab as an embedded 3D viewer, but other online presentation platforms, such as 3DHOP, are explored as well.

Several 3D scanners were tested and compared, which led to the decision to perform all scans with a structured light scanner (SLS), the DAVID SLS-3 (also known as HP 3D

\section{(a)}

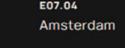



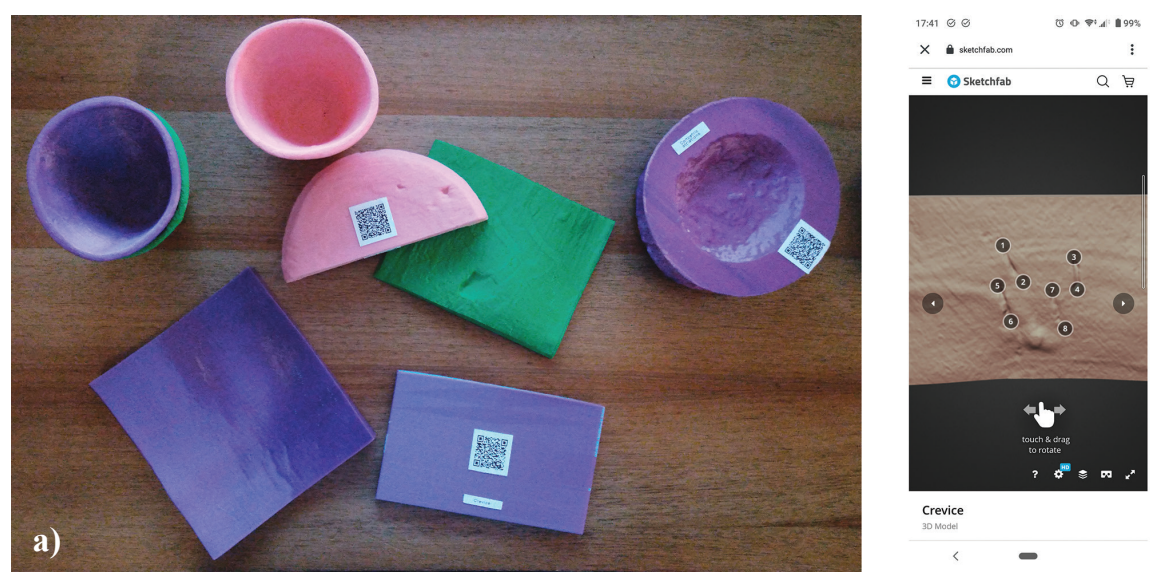

Figure 7. $a-b)$ The 3D printed training set of forming traces (left). QR codes contain links to the online 3D models with embedded information (middle). As such, the $3 \mathrm{D}$ print becomes a meaningful teaching object due to its connection to data (right). Image: L. Opgenhaffen. c) 3D printed objects in a museum setting to encourage public participation. Image: L. Opgenhaffen.
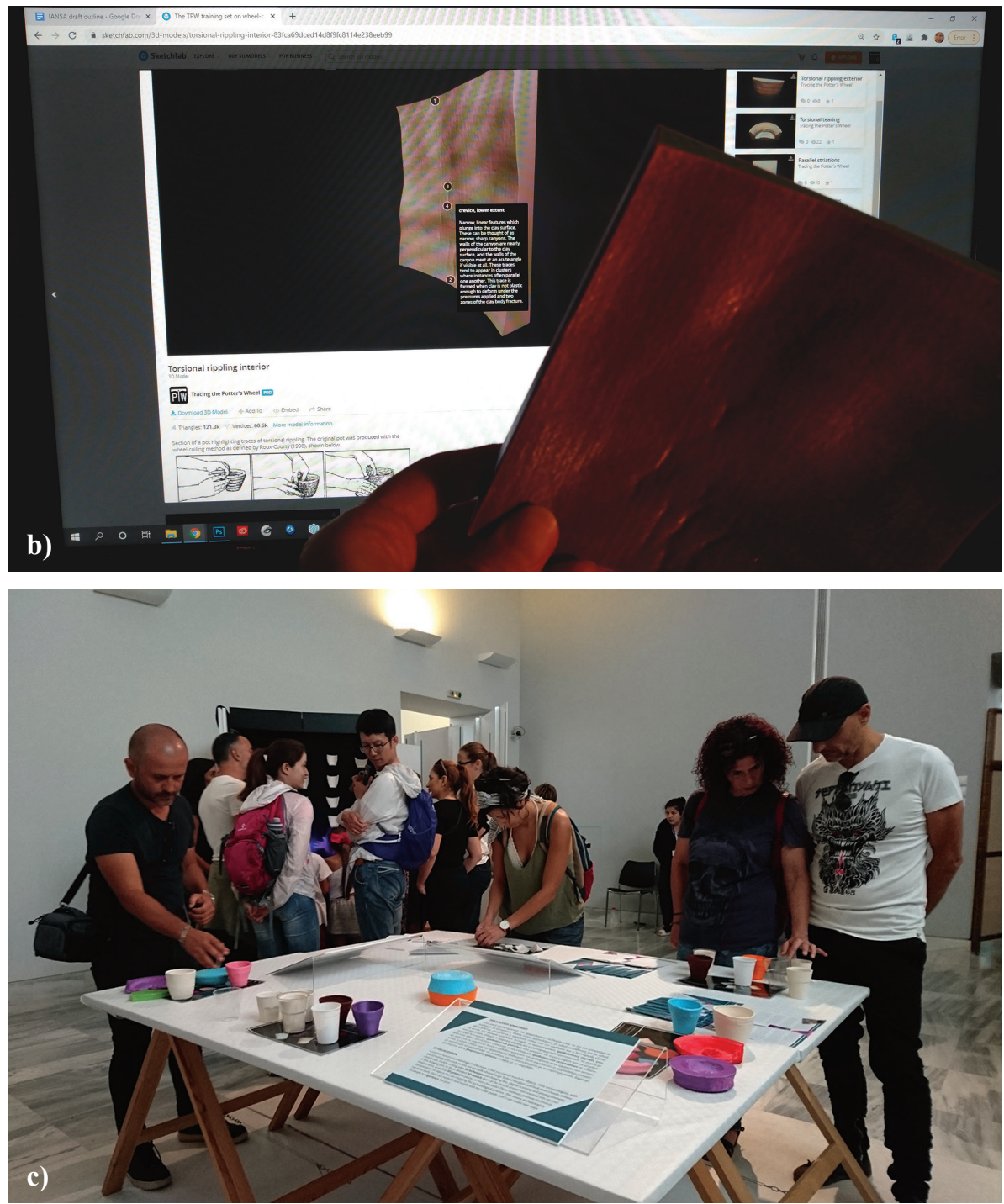

Structured Light Scanner Pro S3). The scans are processed in the native scanner software HP Scan Pro 5 and opensource software Meshlab. This procedure of scanning and processing is recorded in the TPW metadata scheme, which can be found on the project's website. Both $3 \mathrm{D}$ models and the batch of separate scans are saved in multiple file formats and made available for download in TPW's online database, to ensure data transparency, reproducibility and accessibility.
Lastly, TPW is experimenting with 3D prints of both vessels and macrotraces, the latter as a training set, to deploy in teaching students in archaeology and as an effective tool for public outreach (Figures $7 \mathrm{a}-\mathrm{c}$ ).

However, 3D models remain "empty vessels" if they are not connected to contextual data. In 2D visualisations, information about raw data and three-dimensional data is codified, and archaeologists are trained to recognise its 
meaning in almost the blink of an eye. A digital 3D model, however, is able to display untranslated three-dimensional data, and has the potential to embed associated information in an entirely different way, following different choices of data abstraction (Munzner, 2015; Ware, 2013).

\section{Sharing research}

\subsection{Data integration}

Sophisticated investigations combining experimental archaeology, ceramic fabric analysis and 3D visualisation inevitably generate a wide range of datasets. Over the course of fieldwork and analysis, TPW has generated considerable data, composed of multiple file types for images, video footage, 3D models, and texts, as well as the contextual information for those files, including metadata and paradata. It is increasingly recognised that the choice of what data to collect, and in which format, has a direct impact on the archaeological knowledge-making process (Börjesson and Huvila, 2018; Opgenhaffen, in press). For this reason, the project archive was designed to capture and share the fullrange of technologically-focused information about forming techniques for archaeological and experimental ceramics, as the specific needs for presenting an archaeologicallyretrieved object are different from presenting an experimentally-produced object. In the TPW database, information about real material, the pottery, is connected to the 3D model. Photographs, media and written annotations augment the digital 3D model in the database, making them meaningful representations of data and concepts, and a new kind of digital artefact supporting research.

\subsection{The TPW knowledge hub}

The TPW archive for compositional and technological features of wheel-made ceramics was conceived as an online platform from the outset. This visual presentation of data is designed to be a cognitive learning tool while at the same time functioning as a knowledge hub, a place of knowledge creation. The TPW knowledge hub provides high-quality resources and standardised guidelines for researchers to learn to technologically assess assemblages in their own research. Furthermore, specifically-designed learning pathways help to transform the digital archive into an interactive and innovative tool where users are encouraged to explore and contribute to the database.

A learning pathway (LP) has been defined as "a sequence of intermediate steps" from prior conception to a product (or "target model"), "a route of cognitive states" (Clement, 2000; Niedderer and Goldberg, 1995; Scott, 1992), tentatively similar to the concept of chaîne opératoire that TPW applies to investigate past and present practice. LPs are customarily either fixed and formal learning programs (for example, through Massive Open Online Courses (MOOCs)) or flexible and informal ways of learning (for example, through communities of practice, connected learners, multivocal and choice, storytelling and mobile devices). The latter represents a central theme in TPW's overarching framework to study ancient modes of technological transmission within communities of practice in the Bronze Age Aegean. Today, informal LPs offer an opportunity to meet learning modes in modern communities of practice (as developed by Wenger, 1998), such as archaeologists investigating ancient potting practices.

TPW employs an informal LP in which encourages multiple users to follow intelligible clusters of information rather than a structured path of courses. This allows users to have self-determination in the learning trajectories provided for to them, and allows us to tailor these clusters to any entry level (lay, student, specialist). These seemingly random educational offerings entail a short introduction to the topic (forming techniques) and how to use the database, but also incorporate TPW's workflows for collecting, analysing and assessing datasets to ensure usability and reproducibility. Following design thinking, expected user needs were assessed during the planning stage of the database, which has

Table 1. Tracing the Potter's Wheel Project's learning paths. * Learning paths are currently in production at the time of writing of this article. Tracing the Potter's Wheel Project's learning paths can be found at: https://tracingthewheel.eu/.

\begin{tabular}{|c|c|c|}
\hline Learning path type & Medium & Theme \\
\hline \multirow[t]{4}{*}{ research: methods and workflows } & blog/publication & TPW's selection procedures* \\
\hline & blog & TPW's photographic recording procedure* \\
\hline & blog & TPW's fabric analysis procedure \\
\hline & blog & TPW workflow series: SLS scanning manual \\
\hline \multirow[t]{4}{*}{ educational: research objectives } & blog & TPW workflow series: Manual on processing 3D scans \\
\hline & blog & TPW workflow series: metadata and sharing 3D models \\
\hline & blog & 3D printing pots and traces \\
\hline & $3 \mathrm{D}$ prints & 3D training set of macrotraces \\
\hline \multirow[t]{4}{*}{ practical: using online environment } & Video tutorial & how to use the database, browse and search functions* \\
\hline & Video tutorial & how to use the $3 \mathrm{D}$ viewer* \\
\hline & video tutorial/blog & using downloaded 3D files in open-source software* \\
\hline & video tutorial/blog & how to register as contributor and upload a dataset* \\
\hline
\end{tabular}


been discussed in Opgenhaffen, Jeffra and Hilditch (in press). Subsequently, a threefold learning approach was developed (Table 1). The first topic relates to the research procedure, comprising the presentation of data, the accumulation of new data, and the creation and presentation of new knowledge. The second topic is educational, focusing on informing about ancient technology in general and forming techniques of pottery more specifically (Figure 9). The third topic is practical and concerns how to use the database. The LPs are illustrated through either video tutorials, or blog posts, or a combination of both, as well as by $3 \mathrm{D}$ reference collections with tagged 3D models. These models can be downloaded for further exploration and 3D printed for use in classrooms.

LPs are designed to reach as many individuals as possible from diverse backgrounds, so as to allow users to participate - rather than follow assiduously - according to differing needs. For example, an archaeologist with a ceramic assemblage seeking comparative data for wheel use may use the information quite differently to a student embarking on their training for identifying wheel traces on ceramics. The process of building the LP from discrete clusters of information that are accessible to all levels of expertise makes the LP a more inclusive tool.

The need for broadening archaeological data literacy has been recently addressed by Kansa and Kansa (2018, p.89), who emphasise the importance of "making instructional uses of data; strategies to make data more visual, better cited, and more integral to peer-review processes; and pathways to create higher-quality data better suited for reuse". These issues have been tackled by TPW, especially the reusability of data and reproducibility of TPW's workflows. The TPW database on wheel-made pottery is not meant as a static archive where project data is filed away after finishing a project. Instead, it is designed to be an active knowledge hub and a reference collection of wheel-formed pottery. The TPW project data itself, however, will be stored and maintained at the Dutch Data Archiving and Networking Service (DANS), where it receives a DOI (Digital Object Identifier), enabling datasets to be cited too.

\subsection{Encouraging ongoing collaboration}

The creation of a dedicated and open access information hub by the project, which includes TPW's findings, is not the only major asset worth highlighting here. What is worthy of more attention, particularly for those interested in technologically assessing wheel-formed ceramics, is the fact that this information hub is open to - and designed for - contributions by others. TPW's work with KBELL $\&$ POSTMAN to create the hub means there are tested

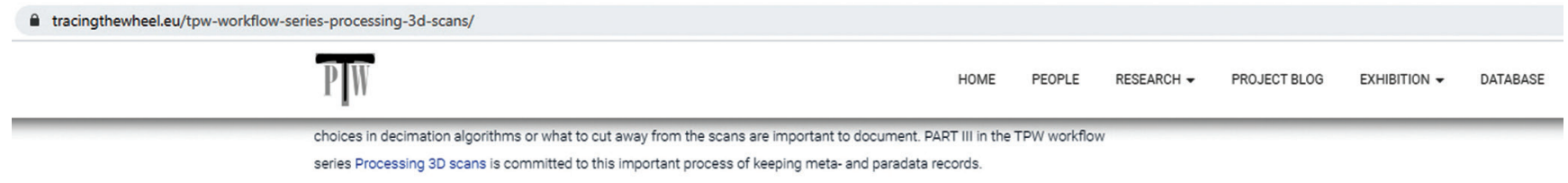

\section{Scanning with DAVID}

\section{What is Structured Light Scanning}

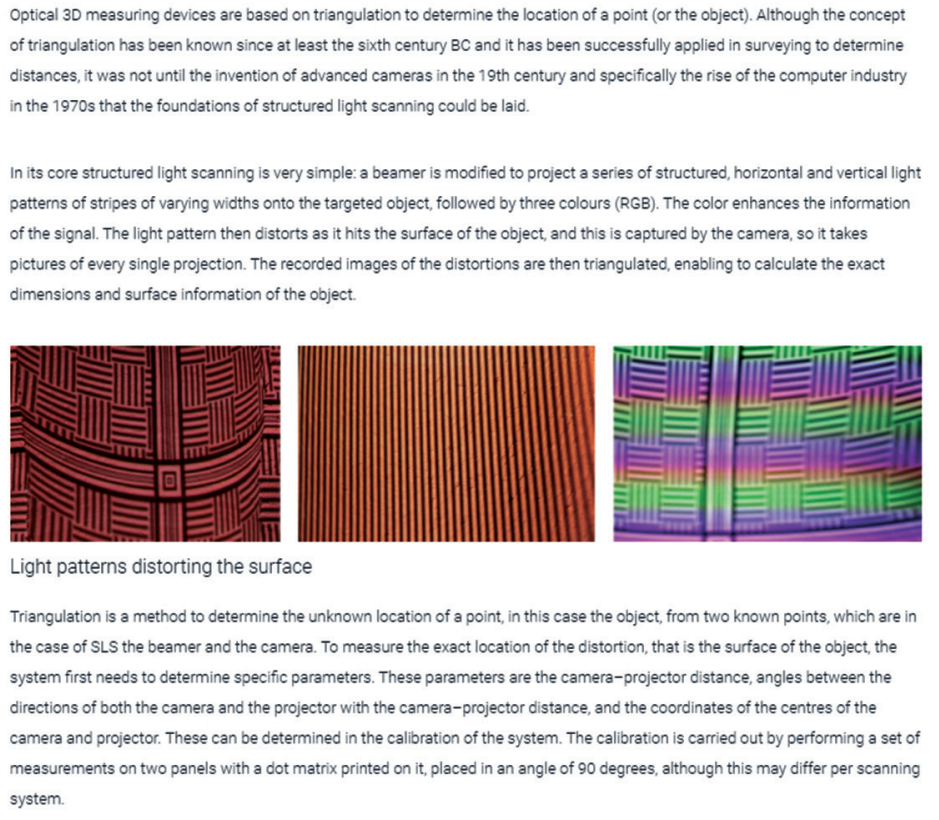

Figure 8. Example of a learning pathway with a student-level research topic: a blog post on 3D scanning. Image: L. Opgenhaffen. 


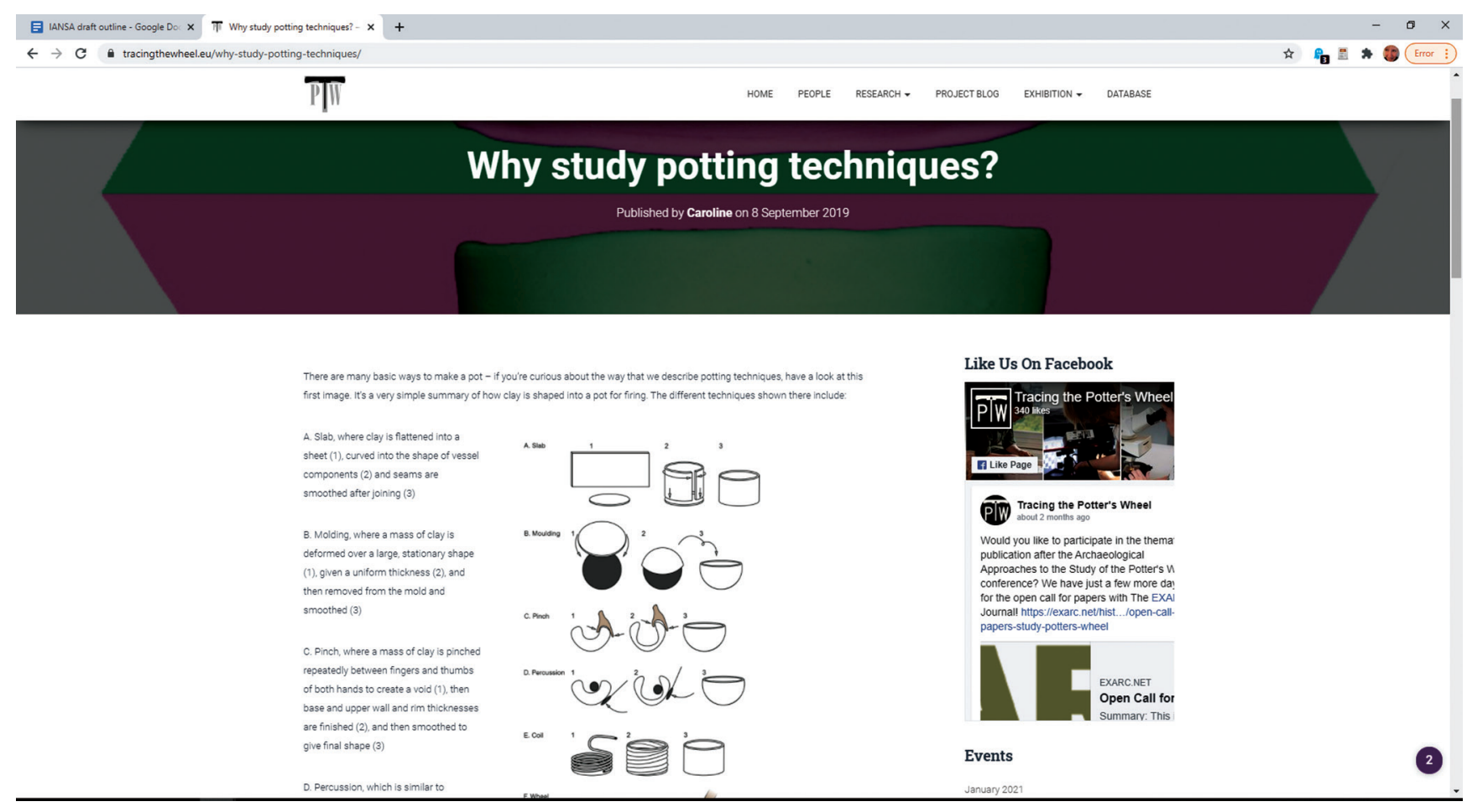

Figure 9. Example of a learning pathway with an entry-level educational topic: a blogpost by Caroline Jeffra about why archaeologists study potting techniques. Image: L. Opgenhaffen.

and user-friendly ways to import data from other projects. Although the TPW project focused on the Aegean in the Late Bronze Age, there are no limitations on the focus of potential contributions; the hub can accommodate any datasets which present information on the nature of wheel use in the archaeological record.

In order to ensure that independent contributions are readily integrated and reliably comparable to existing data within the hub, standards for data reporting procedures should be followed by contributing users. It was for this reason that TPW workflows and best practices have been explicitly shared, as well as standardised data import processes. By standardising not only data collection and recording but also the integration of data, cross-comparison is easier and new datasets can be readily incorporated and searchable in the hub. In particular, the approach taken within the information hub is to dictate the minimum included information for each entry while encouraging participants to provide further details. In this way, archaeological objects included will allow viewers to understand the archaeological contexts from which they come. Similarly, experimental objects will be well described so that their validity as comparative material can be established easily. Photo, video, and 3D models will be welcomed with their accompanying metadata so that they can be seamlessly incorporated and readily useful to visitors. It is through this standardisation that the hub can remain useful to technology specialists and the broader community of archaeologists alike, but it should also be stated that such practices simplify the maintenance of connections to other repositories such as Europeana.
The knowledge hub can be seen as an important step in the democratisation of knowledge sharing; scholars are invited and assisted in contributing their research, and the data itself is freely available for study. Furthermore, visitors are given the tools to advance in their understanding of what the hub presents. Ultimately, with the contribution of more datasets, a better understanding in ancient potting strategies can be reached to trace the potter's wheel well beyond the boundaries of the Aegean Sea.

\section{Summary}

Investigating a complex technology such as the potter's wheel requires a methodology that not only integrates multiple archaeological specialisms, but which also embraces data sharing within an open access environment. Our goals for TPW were twofold: to encourage the uptake of skills within the archaeological community to increase this type of technological study, thereby growing potential datasets that can be applied for characterising the use of potter's wheel; and to promote contributions from other specialists that will facilitate greater comparisons between assemblages. To achieve these goals, the project members of TPW actively sought to standardise and enhance research practices (past and present) through the integration of previously separate archaeological techniques and methods. Thorough documentation of analyst choices within the experiment, fabric analysis and $3 \mathrm{D}$ visualisation components of the project, as well as training manuals for equipment 
use and blogs on how to process the data, TPW provides a substantial resource for future investigations of pottery wheel technology. To make this resource as effective a tool as possible, open access was prioritised throughout the project to facilitate future research on wheel practices in ceramic production within a robust and active community. The final results of TPW will also further our understanding of how the potter's wheel was being used at the key diachronic sites of Knossos and Tsoungiza, thereby contributing to a better understanding of the temporal and spatial patterns of potter's wheel use and development in the Bronze Age Aegean.

\section{Acknowledgements}

The Tracing the Potter's Wheel Project is funded by the Dutch Research Council (NWO) through the VIDI Talent Programme and Aspasia Scheme awarded to J. Hilditch (2016-2021). Additional financial support was given from the following University of Amsterdam units: Amsterdam School for Heritage, Memory and Material Culture (AHM), Amsterdam Institute for Humanities Research (AIHR), Amsterdam University Funds (AUF) and the Faculty of Humanities Archaeology Fund. The TPW project members also gratefully acknowledge logistical support from Digna van der Woude and Astrit Blommenstijn (Faculty of Humanities, UvA). The realisation of the open access repository was made possible due to a Small Data Project (KDP) award from the Dutch Data Archiving and Networked Services (DANS), as well as the assistance and expertise of Ivan Kisjes (UvA), Karissa Bell and Alex Post (KBELL \& POSTMAN), and Kelly Papastergiou (TPW Project Assistant).

\section{References}

BÖRJESSON, L I., and HUVILA, I., 2018. Digital archaeological data for future knowledge-making. In: I. Huvila, ed. Archaeology and Archaeological Information in the Digital Society. New York: Routledge, pp. 1-13.

CHOLEVA, M., 2012. The First Wheelmade Pottery at Lerna: WheelThrown or Wheel-Fashioned? Hesperia: The Journal of the American School of Classical Studies at Athens, 81(3), 343-81.

CHOLEVA, M., 2018. Craft behaviours during a period of transformations. The introduction and adoption of the potter's wheel in Central Greece during the Early Bronze Age. In: I. Caloi, and C. Langohr, eds. Technology in Crisis: Technological changes in ceramic production during periods of trouble. Louvain: Presses Universitaires de Louvain, pp. 45-74.

CHOLEVA, M., 2020. Travelling with the potter's wheel in the Early Bronze Age Aegean. Annual of the British School at Athens, 115, 1-46.

CHOLEVA, M., JUNG, R., and KARDAMAKI, E., 2020. Working on the potter's wheel: technological insights into Mycenaean pottery production. Egypt and the Levant, 30, 219-282.

CLEMENT, J., 2000. Model based learning as a key research area for science education. International Journal of Science Education, 22(9), 1041-1053. DOI: 10.1080/095006900416901

GOROGIANNI, E., ABELL, N., and HILDITCH, J., 2016. Reconsidering Technological Transmission: The Introduction of the Potter's Wheel at Ayia Irini, Kea, Greece. American Journal of Archaeology, 120(1), 195-220.

HÄGG, R., and MARINATOS, N., eds., 1984. The Minoan Thalassocracy: Myth and Reality; Proceedings of the Third International Symposium at the Swedish Institute in Athens, 31 May-5 June 1982. Skrifter Utgivna av Svenska Institutet i Athen, 4. Göteborg: Paul Åström's Förlag.

HARRIS, R., and RAINEY, L., 2012. Learning pathways between and within vocational and higher education: Towards a typology? Australian Educational Researcher, 39(1), 107-123. DOI: 10.1007/s13384-0120052-1

HILDITCH, J., 2019. The pottery fabrics and technologies of Phases B-C. In: I. Nikolakopoulou. Akrotiri, Thera. MBA pottery and stratigraphy. Vols. I-II. Athens: Archaeological Society, pp. 377-470.

HUGGETT, J., 2020. Is Big Digital Data Different? Towards a New Archaeological Paradigm. Journal of Field Archaeology, 45(1), S8-S17. DOI: $10.1080 / 00934690.2020 .1713281$

JEFFRA, C., 2019. Forming Technology. In: I. Nikolakopoulou, ed. Akrotiri, Thera. Middle Bronze Age Pottery and Stratigraphy. Vols. I-II. Athens: Archaeological Society, pp. 471-477.

JEFFRA, C.D., 2013. A Re-examination of early wheel potting in Crete. Annual of the British School at Athens, 108, 31-49.

JEFFRA, C.D., 2021. Generalised type sets in experimental ceramics: widening applicability and maximizing cross-cultural assessments, Interdisciplinaria Archaeologica, Natural Sciences in Archaeology, 12(2), 173-179.

KANSA, S.W., and KANSA, E.C., 2018. Data Beyond the Archive in Digital Archaeology. Advances in Archaeological Practice, 6(2), 89-92. DOI: 10.1017/aap.2018.7

KNAPPETT, C.J., 1999. Tradition and Innovation in Pottery Forming Technology: Wheel-Throwing at Middle Minoan Knossos. Annual of the British School at Athens, 94, 101-29.

MACDONALD, C.F., HALLAGER, E., and NIEMEIER, W-D., eds, 2009 The Minoans in the central, eastern and northern Aegean-new evidence. Monographs of the Danish Institute at Athens. Athens: Danish Institute at Athens.

MUNZNER, T., 2015. Visualization Analysis and Design. Boca Raton: CRC Press/Taylor \& Francis Group.

NIEDDERER, H., and GOLDBERG, F., 1995. Learning Pathway and Knowledge Construction in Electric Circuits. Lecture presented at the European Conference on Research in Science Education in Leeds. https://citeseerx.ist.psu.edu/viewdoc/summary?doi=10.1.1.30.2839 - accessed Jan 2021.

OPGENHAFFEN, L., in press. Visualizing Archaeologists. A reflexive history of visualization practice in archaeology. Open Archaeology.

OPGENHAFFEN, L., JEFFRA, C.D., and HILDITCH, J., in press. Balancing data storage and user functionality: The 3D and archaeological data strategy of the Tracing the Potter's Wheel Project. In: M. Hostettler, A. Buhlke, C. Drummer, L. Emmenegger, J. Reich, and C. Stäheli, eds. The 3 Dimensions of Digitalised Archaeology: State-of-theart, Data Management and Current Challenges in Archaeological 3D-Documentation. Cham: SpringerOpen.

RENFREW, A.C., 1972. The Emergence of Civilisation: the Cyclades and the Aegean in the Third Millennium BC. London: Methuen.

ROUX, V., 2003. A Dynamic Systems Framework for Studying Technological Change: Application to the Emergence of the Potter's Wheel in the Southern Levant. Journal of Archaeological Method and Theory, 10(1), 1-30.

ROUX, V., 2009. Technological Innovation and Developmental Trajectories: Social Factors as Evolutionary Forces. In: M. J. O’Brian, and S. Shennan, eds. Innovations in Cultural Systems: Contributions from Evolutionary Anthropology. Cambridge, Massachussetts: MIT Press.

ROUX, V., and JEFFRA, C., 2015. The Spreading of the Potter's Wheel in the Ancient Mediterranean: A Context Dependent Phenomenon. In: W. Gauss, G. Klebinder-Gauss, and C. von Rüden, eds. The Transmission of Technical Knowledge in the Production of Ancient Mediterranean Pottery. Vienna: Austrian Archaeological Institute, pp. 165-182.

RUTTER, J.B., 2013. "Minding the Gap": From Filling Archaeological Gaps to Accounting for Cultural Breaks. A 2013 Perspective on a Continuing Story. American Journal of Archaeology, 117(4), 593-7.

SCOTT, P., 1992. Conceptual pathways in learning science: A case study of one student's ideas relating to the structure of matter. In: R. Duit, F. Goldberg, and H. Niedderer, eds. Research in physics learning: Theoretical issues and empirical studies: Proceedings of an international workshop held at the University of Bremen, March 4-8, 1991. Kiel: Institut für die Pädagogik der Naturwissenschaften an der Universität 
IPN, pp. 203-224.

SOTIRAKOPOULOU, P., 1993. The chronology of the "Kastri Group" reconsidered. Annual of the British School at Athens, 88, 5-20.

SAHOĞLU, V., 2007. Interregional contacts around the Aegean during the Early Bronze Age. Anatolia, 27, 97-120.

WARE, C., 2013. Information visualization perception for design. $3^{\text {rd }}$ ed. Waltham: Elsevier/MK.
WENGER, E., 1998. Communities of practice: Learning, meaning, and identity. Cambridge: Cambridge University Press.

WHITBREAD, I., 2017. Fabric Description of Archaeological Ceramics. In: A. Hunt, ed. The Oxford Handbook of Archaeological Ceramic Analysis. Oxford: Oxford University Press, pp. 200-216. 
